\title{
Autonomia municipal e o federalismo fiscal brasileiro ${ }^{1}$
}

\author{
Municipality's autonomy and brazilian's fiscal federalism
}

\author{
Camila Nayara Giroldo ${ }^{2}$ \\ Marlene Kempfer ${ }^{3}$
}

\section{Resumo}

O presente artigo objetiva analisar a situação do Município perante o Pacto Federativo brasileiro, no que tange a sua autonomia financeira. Para tanto, examina-se o seu enquadramento como membro federativo no que tange à sua autonomia, demonstrando que efetivamente o Município só a gozará de forma plena quando alcançar sua independência financeira. Verifica-se, por meio da análise orçamentária do Município que a gênese do seu déficit econômico se encontra na repartição constitucional de competências para a instituição de tributos cuja arrecadação é economicamente insuficiente (Art. 145 II e III; Art. 149A e Art. 156 Constituição Federal), fazendo com que dependa de transferências intergovernamentais, notadamente o Fundo de Participação dos Municípios. Este sistema não fortalece o federalismo cooperativo, à medida que torna o Município vulnerável em relação às políticas tributárias dos demais membros federativos.

Palavras-chave: Federação. Federalismo fiscal. Autonomia financeira municipal. Receita municipal. Transferências intergovernamentais

\section{Abstract}

This work intends to analyze municipality's situation before Brazilian's federative agreement, as regards to its financial autonomy. Therefore, it examines the framing of municipalities as a federative member before the country's historical evolution, pointing out that, municipality will enjoy full autonomy only when it succeeds on obtaining its financial autonomy. It observes that the root of municipality's economic decrease is located on the distribution of public revenue, that relegates to the member economically inexpressives local taxes, and preconizes a greater amount of intergovernmental transferences, which doesn't enhance cooperative federalism, because it places municipality under the custody of the other members of federal's agreement. Overviewing quantify the lack of municipality's own recources, it uses as paradigm the public finances of Londrina's municipality. Therefore, among the causes which generate the difficulties for social-economical development of municipalities, it finds the formation of its renevue, which is composed by its own resources, due to the exercise of its tributary jurisdiction (Art. 145 II e III; Art. 149-A e Art. 156 Constituição Federal), as well the transferences of States and the Union. This centralized financial pattern doesn't contributes for municipality's federative autonomy. On the contrary, it stimulates its absolute dependence. In order to improve scientific research, it chooses the empiric and

\footnotetext{
Trabalho de Conclusão de Curso.

Discente Universidade Estadual de Londrina.

Docente Universidade Estadual de Londrina.
} 
dedutive methods to represent the bases of analytical procedure, highlighting the use of real financial data with the main scope of developing the issue in a better way.

Keywords: Federation. Fiscal federalism. Municipality's financial autonomy. Revenue municipality. Intergovernmental transfers.

\section{Introdução}

Conforme preconiza a Constituição Federal brasileira de 1988, a forma de organização político-administrativa do Estado é a federativa (Art. $18 \mathrm{CF} / 88$ ), o que representa que mais de um ente de direito público interno pode ser considerado fonte de poder autônomo. Ocorre que a Federação brasileira apresenta uma peculiaridade quanto ao modelo clássico de pacto federativo, à medida que inclui o Município como integrante da Federação, no mesmo patamar hierárquico da União e dos Estados-membros, participantes por excelência dessa forma de Estado.

Ao elevar o Município à condição de ente federativo a Carta Magna de 1988 também garantiu ao mesmo as autonomias administrativa, política e financeira necessárias para o desempenho de suas funções sem a ingerência dos demais membros. No entanto, deve-se observar que a autonomia para a consecução de suas competências materiais consitucionais encontra-se apenas formalmente concretizada devido a insuficiência de receitas próprias.

Diante de tal problematização, tem se como objetivo analisar o Município no federalismo fiscal brasileiro e a dependência econômica das transferências intergovernamentais para a composição da sua receita, tornando-o vulnerável à política financeira diante dos demais entes, notadamente, no caso das transferências voluntárias.

\section{Federalismo Fiscal Brasileiro}

O fenômeno do Federalismo Fiscal está intrinsecamente ligado aos conceitos de federalismo cooperativo, orçamento público, competências materiais e recursos para cumpri-las, consistentes em sua própria capacidade tributária e transferências financeiras, culminando, finalmente na própria autonomia dos membros, que por vezes, são 'amarrados' através da vinculação de sua receita. 
A conceituação de Regis Fernandes de Oliveira (2008, p. 40) acerca do termo 'Federalismo Fiscal' envolve a suficiência da receita do ente, de modo a lhe garantir a consecução satisfatória de suas competências, ou seja, "significa a partilha dos tributos pelos diversos entes federativos, de forma a assegurar-lhes meios para o atendimento de seus fins", sendo que para tanto, mister se faz, coadunar no texto magno, as necessidades financeiras do membro com os encargos que lhe são atribuídos.

Percebe-se através de uma interpretação sistemática da Constituição Federal brasileira, analisando conjuntamente os dispositivos que tratam das competências próprias para a instituição de tributos, que o governo da União mantém a concentração dos tributos, em que pese os encargos estarem se descentralizando para as outras unidades federativas. Tomando em consideração tal assertiva, revela-se o desequilíbrio vertical na Federação, no que tange à titularidade do tributo, ou como denomina Sérgio Prado (2006), exsurge-se a 'brecha vertical', consistente na necessidade das transferências da União para os demais entes, de quantias vultosas, a fim de aumentar a capacidade de gasto dos governos estaduais e municipais, tendo em vista que apenas com sua receita própria tais membros federativos não conseguiriam perfazer suas competências materiais insculpidas na Constituição Federal, quedando-se estagnados em seu desenvolvimento.

O desequilíbrio fiscal tem uma conotação negativa, no entanto, o sistema federativo brasileiro, de característica centralizada no governo da União desde a sua instituição, não poderia se configurar de outra forma sob o prisma do princípio do federalismo cooperativo, pois, tendo a União controle de uma parte maior de tributos, pode executar o repasse para os demais entes não somente de forma devolutiva como também de modo redistributivo. Outros fundamentos para a concentração de renda na esfera da União seriam a promoção do equilíbrio na oferta de bens públicos locais de modo a equalizar as jurisdições em seu aspecto de dispêndio com os serviços públicos, apesar da crítica relativa à divergência entre os custos nas diversas unidades federadas.

Para quantificar a brecha vertical, isto é, para verificar o quantum necessário a ser repassado da União para os outros membros federativos, por meio das transferências verticais, é necessário então, analisar a parcela da receita recebida de forma autônoma pelo ente beneficiado em face dos encargos de sua competência. Assim, Sérgio Prado (2006, p. 80) elenca como formas mais usuais de verificação da brecha vertical "a relação entre 
recursos próprios e gastos totais ou, alternativamente, a relação entre recursos próprios dos governos subnacionais e recursos a eles transferidos pelo governo central."

Conforme insculpido nos Arts. 153, 155 e 156, pertencentes ao Título VI- Da tributação e do Orçamento, Capítulo I - Do Sistema Tributário Nacional da Constituição Federal, alguns dos principais impostos são atribuídos ao controle da União, e tal consideração tem suas implicações positivas e negativas à luz do princípio federativo, à medida que, concentrando mais tributos em seu âmbito de poder pode redistribuí-los de forma equitativa, mas, por outro lado, gera a dependência financeira.

Preliminarmente, é necessário recordar que a Federação pátria foi formada de modo centrífugo, portanto, tende ao poder centralizador da União. Ademais, tal membro central, embora não seja hierarquicamente superior aos outros, guarda algumas competências de suma importância para a Federação como um todo, no sentido de fortalecer o próprio pacto originário, devendo zelar pela uniformidade entre os entes locais, manifestada através das transferências 'equitativas'.

A União, como ente central, e principal detentor dos tributos gerados, deve transferir uma parcela, já previamente estipulada nos Arts. 157 a 159 da Constituição Federal, do montante recebido para os demais entes, à título de devolução, pois, em regra, os membros locais poderiam ter a competência para a arrecadação de tais tributos, no entanto, a titularidade queda-se com a União, e os entes aludidos recebem posteriormente, como transferências, razão pela qual, podem denominar-se transferências devolutivas. Insta salientar, que tal receita não pode sofrer prévia vinculação como condição ao repasse, nos termos do Art. 160 da Carta Magna, ressalvando-se o parágrafo único do dispositivo legal aludido, bem como não deve servir de 'compensação' da dívida do ente beneficiário com o crédito do ente transferidor, devendo haver apenas a retenção do valor até o adimplemento. Ademais, o quantum recebido é proporcional à capacidade arrecadatória de cada ente, portanto, não tem qualquer finalidade redistributiva, na medida em que mantém o status quo dos membros, repassando aos que mais arrecadam, a maior parte da receita.

Contudo, subsistem também, as transferências cujo fundamento de sua existência não se refere à devolutividade da verba, mas sim, à promoção do equilíbrio socioeconômico entre os membros, de modo a alcançar um padrão nacional. A equalização de receita permite que os entes auferidores de menor arrecadação possam obter renda suficiente para 
perfazer seus encargos assumidos e promover seu desenvolvimento. As diferenças de arrecadação não se verificam apenas entre entes diversos, mas também entre as entidades locais entre si. Se só houvessem transferências devolutivas, os membros mais pobres em arrecadação estariam em franca desvantagem em relação aos que mais auferem, oferecendo bens e serviços de forma ineficiente, e, para manter o mesmo nível no oferecimento dos serviços públicos desses, teriam que aumentar o valor dos tributos de seus habitantes, situação que feriria frontalmente a isonomia tributária.

Ao contrário da receita devolutiva, sua base de distribuição pode ser embasada em diversos fatores, v.g, população, IDH (Índice de Desenvolvimento Humano), ou qualquer outra margem que demonstre a real necessidade do repasse. Na federação pátria, ao invés de profundos estudos acerca das verdadeiras necessidades de cada ente, analisados de forma individual e autônoma, há a instituição dos fundos de participação, tratados posteriormente, no presente trabalho. Ademais, outras críticas podem ser elencadas em relação a tal sistema de repasse financeiro, pois, para que o fim de equalização entre os entes seja realizado materialmente, é necessário que não haja a transferência de recursos "dos pobres das jurisdições ricas para os ricos das jurisdições pobres", conforme preleciona Edilberto Carlos Pontes Lima (2003, p.130).

Como já afirmado alhures, a descentralização de competências materiais para os estados-membros e municípios, junto com sua falta de verbas para custeá-las gera a 'brecha vertical'. Ocorre que de acordo com decisões políticas o governo central decide relegar aos demais entes a execução de certos "projetos e objetivos de interesse nacional", nos termos de Sérgio Prado (2006, p. 21) e para tanto, deve transferir quantia compatível com o dispêndio a ser suportado pelo membro federativo. Portanto, esse terceiro tipo de transferência é vinculado às finalidades predefinidas por outro ente, e seu quantum é definido em sede da elaboração do orçamento, não em dispositivos prefixados.

Essa situação pode ocasionar a atenuação da autonomia política e orçamentária do membro destinatário, representando uma ingerência incompatível com o modelo federativo, bem como, a valorização dos entes autônomos que representem a base política do Executivo. Por outro lado, sob o prisma da União, é necessária tal vinculação para a consecução de serviços de natureza nacional, e por representarem tal ordem de importância, busca-se prevenir a má alocação dos recursos, afinal, cada unidade federativa 
local visa o seu próprio desenvolvimento, ainda que em detrimento dos demais membros, como se demonstra através da 'guerra fiscal', dessa forma, se tais recursos fossem transferidos, sem a devida vinculação ou a exigência de condições, é provável que os entes beneficiados se distanciassem do projeto original para conseguirem um maior bônus somente para a sua localidade.

O governo central pode fiscalizar a utilização das verbas instituindo um padrão mínimo dos serviços descentralizados, como condicionalidade ao repasse, diferenciando-se das demais transferências. Apesar de serem transferências livres, ou voluntárias, como todos os atos administrativos guindados pelo princípio da legalidade, os administradores devem fazer o que a lei permite, portanto, tais transferências estão previstas nos seguintes dispositivos legais: Constituição Federal, a Lei Complementar n.우 101/2000 e as leis de diretrizes orçamentárias e anual.

O grande problema das receitas livres está no seu próprio conceito, pois, como impera em sua transferência o critério político, a finalidade do repasse pode ser maculada e modificada para, invés da execução de serviços de interesse nacional, o apaniguamento de membros que tenham afinidade política com o governo central, na medida em que, devido ao seu caráter de discricionariedade, entes federativos governados pelo mesmo partido político ou mesma coligação que o chefe do Executivo, podem ser beneficiados no orçamento, no que tange às transferências.

Como dantes aludido, existem as transferências previamente estipuladas em dispositivos legais, de natureza obrigatória, e as definidas periodicamente nas leis orçamentárias, consideradas 'livres' em face do seu caráter discricionário. Ocorre que, na realidade financeira da Federação, por vezes, não é tão simples separar as duas modalidades de transferências, nos termos de Sérgio Prado (2006, p. 39) "encontramos frequentemente situações em que não há qualquer dispositivo legal que obrigue a existência daquele fluxo de recursos, mas ele assume um caráter permanente", devido ao decurso de tempo em que foram ofertados, em razão, muitas vezes, da acomodação dos beneficiários.

A brecha vertical (disparidade entre encargo e receita própria) tenta ser resolvida através das transferências, como suprarreferido. No entanto, o repasse, que deveria ser norteado por critérios orçamentários, mediante a análise de receita e despesa, na realidade, se rege por critérios eminentemente políticos, isso se deve à dificuldade em aferir o 
quantum a ser despendido por cada ente, pois, em uma Federação de dimensão continental como a brasileira, a variação de preços se posta como um adversário à mensuração dos gastos.

Em suma, não se deve olvidar que a Constituição brasileira de 1988, primando pelo 'estado do bem estar social' aumentou suas competências albergando diversos direitos sociais como serviços públicos, e os têm descentralizado para a responsabilidade dos entes federativos locais, que, exauridos em seu orçamento, se vêem reféns das transferências da União para executar seus encargos. Dessa forma, houve a inversão da 'Lei de Say fiscal', pois, deveria haver primeiro a descentralização financeiro-orçamentária (PRADO, 2003, p. 43) para que os governos locais pudessem desenvolver seus encargos de modo autônomo.

Pode-se elencar, de acordo com Sérgio Prado (2003, p. 54) como receita devolutiva o salário educação; o imposto sobre operações financeiras-ouro; imposto territorial rural; 75\% (setenta e cinco por cento) da cota-parte do ICMS; receita redistributiva interna: Fundef interno (recursos do ICMS, IPI-EXP e LC 87) e as cotas-parte de $25 \%$ do ICMS, IPI-EXP (cota municipal) e seguro receita (cota municipal); receita redistributiva interestadual: SUS; Fundef- complementação federal; Fundef - recursos dos fundos de participação e fundos de participação Estados e Municípios. Por outro lado as transferências voluntárias ${ }^{4}$ são limitadas através da Lei da Responsabilidade Fiscal e disponibilizadas através de consórcios e convênios públicos.

O ponto central do Federalismo Fiscal refere-se à divisão de encargos entre os entes federados e a atribuição de tributos que possam custeá-los. Para tanto, o legislador deve ser guiado por critérios de eficiência e operacionalidade em sua escolha.

Assim, o grande desafio do Federalismo Fiscal se torna compatibilizar os encargos traçados pela estrutura normativa e os instrumentos fiscais capazes de custear sua execução, bem como a titularidade de tal receita, e, enfim buscar "mecanismos que permitam maior eficiência na arrecadação de tributos, maiores benefícios na partilha e no próprio gasto, tudo sob um critério que garanta uma redistribuição justa e equitativa das receitas em todo o território", como preconiza João Francisco Neto (2009, p. 51).

Para ilustrar o percentual de arrecadação dos entes federativos proveniente dos tributos próprios colaciona-se o gráfico abaixo, referente aos valores do ano de 2002:

4 Obs. À época vigorava o regime de transferências relativo ao Fundef. 
Gráfico 1 - Arrecadação direta.

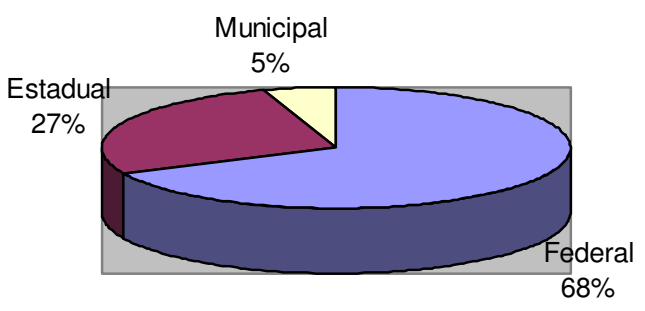

Fonte: Informe-se n. 54, BNDES, apud Barbosa; Barbosa, 2005, p. 313.

Dessa forma, percebe-se que a União visa concentrar a receita tributária, para que em segundo momento, possa repartir do 'bolo tributário' com os demais entes, fazendo da receita uma 'colcha de retalhos', na medida em que se constituem de diversos tipos de transferências, sejam devolutivas; ou a fim de suprir deficiências financeiras dos entes, de forma equitativa, traduzindo o princípio da igualdade material, consistente em tratar os desiguais na medida de sua desigualdade, e ainda, para a materialização de algum interesse supraestadual ou municipal, de interesse de toda a Federação, sendo que tal parcela vincula os Executivos locais à administração dos interesses preconizados da União, cerceando sua autonomia financeiro- administrativa.

\section{Federalismo Cooperativo}

A Federação brasileira se compõe por meio do pacto indissolúvel entre União de Estados-membros e Municípios, portanto, verifica-se em sua própria gênese que nas relações entre tais entes deve prevalecer a cooperação, pois, se todos estão interligados visando objetivos comuns, como de fato ocorre em uma união, a prosperidade e desenvolvimento de um deve trazer benefícios aos demais. No entanto, no caso da Federação pátria, não se preconiza atos positivos para a melhoria das relações entre os membros, ao invés disso, privilegia-se atitudes omissivas, ou seja, agir de modo que não atrapalhe ou prejudique o outro ente, reprimindo-se conduta contrária, sendo que são escassas ou inexistentes políticas de incentivo à cooperação positiva. 
Por outro lado, alguns conflitos entre os componentes da Federação são de sua própria natureza devido à descentralização de poder, verifica-se que não raras vezes, um de seus integrantes acaba por afrontar a autonomia de outro, ou mesmo auferir, de modo predatório, mais benefícios, principalmente financeiros, em detrimento dos outros membros, ressalvado o Art. 151, inc. I da Constituição Federal, pois, tal dispositivo prima pela igualdade material ao preconizar o papel extrafiscal da concessão de incentivos, sendo que por meio desse mecanismo a União visa fomentar o equilíbrio socieconômico entre as regiões do País. Logo, a Constituição como pacto federativo, deve priorizar que todos os componentes sejam tratados de modo equânime, a fim de que um deles não se agigante perante o outro, tornando-se uma relação de dependência político-financeira. Nesse diapasão, tanto a União não deveria centralizar a arrecadação de tributos, quanto os demais entes não poderiam externalizar todas, ou a maioria, das suas despesas para o ente central ou os contribuintes. Um exemplo da externalização de despesas ocorre quando uma municipalidade, ao invés de conseguir recursos para a construção de hospitais em seu território, prefere de forma mais cômoda, adquirir ambulâncias para transportar sua população à outro município a fim de que usufrua de tal serviço.

Fernando Luiz Abrucio e Valeriano Mendes Ferreira Costa (1998, p. 36-37) suscitam que a Federação brasileira se caracteriza como competitiva devido ao maior equilíbrio entre os estados; desigualdades regionais; descrença nos mecanismos de correção desses desequilíbrios; a ausência de instituições adequadas para coordenar a competição e a falta de regras institucionais que incentivem a cooperação entre os estados.

Outro fato desagregador que inibe a integração entre municípios é a política da distribuição de fundos de participação, visto que se torna muito mais lucrativo o desmembramento de municípios e a emancipação de distritos, do que efetuarem convênios com outras localidades próximas, dessa forma, obtém uma 'fatia' de tal transferência. Ademais, não há uma política de incentivo à cooperação entre os municípios que poderia potencializar sua ação, à medida que haveria a formação de grupos para a consecução de serviços públicos de melhor qualidade.

Não obstante as várias críticas, há também o lado positivo da competição, porquanto, dessa forma cada governo busca a melhor qualidade de seus serviços em comparação com outros integrantes, bem como, 


\begin{abstract}
a pressão pela redução dos níveis de tributação interna tende a contrabalançar as pressões pela elevação dos gastos e tende promover a maior eficiência, na medida em que obriga o governo a examinar criticamente seus gastos; a possibilidade de se realizarem experiências na política tributária com resultados benéficos e a agilidade na adequação da tributação às novas circunstâncias econômicas (ABRUCIO; COSTA, p. 52).
\end{abstract}

Contudo, não se deve esquecer que a guerra fiscal desenfreada entre os membros federativos não traz benefícios para nenhum dos participantes desse jogo, que cada vez mais concedem privilégios fiscais, em detrimento do seu próprio orçamento e das finanças dos outros membros, diminuindo assim, a qualidade dos serviços públicos devido à menor arrecadação e aumentando as dívidas estatais, deve-se levar em conta como tais renúncias serão financiadas.

Ademais, para a conceituação de federalismo cooperativo, deve-se atentar também para a divisão de competências entre os entes federativos, que pode ocorrer de forma horizontal, criando as competências privativas de cada membro, onde os titulares não podem sofrer ingerências dos demais, no caso dos Municípios, estão elencadas no Art. 30 da Constituição Federal. Por outro lado, existem as competências suplementares e comuns que devem ser exercidas por todos os integrantes da Federação, de forma coordenada, representando a divisão 'vertical' de tarefas.

Ao tratar dos temas Federação e cooperação, Dalmo de Abreu Dallari (2007, p. 262) afirmou que "[...] é preciso considerar que a federação, quando autêntica, exige o tratamento igual de todos os componentes, o que na prática pode ser um mal, criando uma solidariedade forçada e meramente formal." Uma relação de cooperação deve guiar-se pelo princípio da igualdade material, ou seja, tratar os desiguais na medida de sua desigualdade, nos termos preceituados no Art. 151, inc. I da Constituição Federal.

No que tange à parte financeira, a cooperação tem se dado por meio da repartição de rendas, pois, o sistema de atribuição exclusiva de tributos pode ser falho, no sentido da equitatividade, ao não considerar as peculiaridades de cada ente federativo, de modo que a incidência do fato gerador do tributo estabelecido como privativo de um ente federativo pode ocorrer mais frequentemente em uma localidade do que em outra, de modo que tal tributo não beneficie os membros de forma igualitária. Diante dessa situação, há o partilhamento de tributos através dos fundos de participação, preconizados no Art. 159 da Constituição Federal, que visam complementar a renda do ente beneficiado. Contudo, 
defende-se que tal modelo de repasse financeiro não está exatamente de acordo com o espírito cooperativo que deve imperar em uma Federação, mas ao revés, presta-se para vincular ainda mais os Municípios e estados-membros ao 'império' da União, que centraliza a receita.

Priorizando a cooperação como meio adequado para fortalecer o pacto federativo, a Proposta de Emenda à Constituição n.o 233/2008, que ainda tramita pelo Congresso Nacional, visa efetuar uma reforma tributária, que dentre outras proposições, visa ampliar "a solidariedade fiscal entre a União e os entes federados, corrigindo distorções e dando início à um processo de aprimorando do federalismo fiscal no Brasil" (FRANCISCO NETO, 2009 , p. 168)", com medidas como a renovação do Conselho Nacional de Política Fazendária - Confaz-, que poderá revogar os incentivos fiscais concedidos posteriormente à 05 de julho do ano de 2008 com o quórum de maioria absoluta desde que haja no mínimo, um representante de todos os estados e o Distrito Federal, bem como instituindo a punição para os membros infratores que concederem tais incentivos sem a aprovação do órgão aludido, consistente na proibição do recebimento do Fundo de participação dos estados, bem como os novos tributos: Fundo de equalização de receitas e Fundo nacional de desenvolvimento regional.

Outro importante avanço no sentido de minimizar a guerra fiscal é a regulamentação do ICMS ser realizada por uma única lei, de caráter nacional, que buscará a equanimidade entre os membros. Apesar de trazer tais punições e caminhar no sentido da repressão ao federalismo predatório, a proposta não tratou de incentivar os convênios entre municípios, solução para aumentar sua capacidade de execução dos serviços públicos de uma forma menos onerosa ao contribuinte, embora o Art. 241 da Constituição Federal preconize os consórcios públicos como meio de cooperação, posteriormente, regulamentados através da Lei $11.107 / 2005$. Os consórcios públicos representam importante alternativa aos Municípios que não conseguem, por meio de renda própria, auferir quantia suficiente para perfazer seus encargos, haja vista que, unindo-se podem executar projetos de infraestrutura considerados caros de interesse público comum às municipalidades envolvidas. 


\section{Autonomia Municipal}

O Município como membro da Federação, goza de autonomia, que etimologicamente deriva do termo grego e significa governar-se conforme suas próprias leis. O vocábulo também

possui diversas acepções jurídicas. Em sentido amplo, designa a liberdade de ação de que dispõem determinados agentes, observados certos limites, materiais ou territoriais [...] autodeterminação [...] balizada, posto não se confundir com soberania [...] desdobramento da forma de Estado adotada (DIMOULIS, 2007, p. 34-35)

Para efetiva autonomia plena é imprescindível que se perfaça a autonomia financeira, a fim de sustentar as demais competências do ente, sem que dependa economicamente dos demais. Tal situação se revela corriqueira no que tange aos membros municipais. Embora ao longo dos anos os Municípios tenham auferido mais parcelas em razão das transferências intergovernamentais, tal ganho financeiro ainda não é capaz de satisfazer todas as necessidades de tal integrante federativo, de forma a persistir uma 'tutela' que afeta o cerne do princípio federativo e o enfraquece, à medida que minimiza a autonomia por meio da equivocada política de repartição de rendas.

A autonomia municipal é considerada um princípio, conforme se depreende do Art. 34, inc. VII, alínea c) da Constituição Federal, resguardado sumamente, haja vista que o membro federativo que transgredi-lo poderá sofrer a intervenção da União, dessa forma evidencia-se a importância desse princípio, a sua inobservância representa um desrespeito para com o próprio princípio federativo, e para restaurá-lo, é necessária a medida extrema da intervenção, que representa exceção à regra. Portanto, a autonomia e a isonomia municipais são asseguradas em âmbito constitucional.

As competências dos Municípios elencadas nos Arts. 29 e 30 da Constituição Federal não representam normas meramente programáticas, não são meros 'conselhos', mas sim, devem ter eficácia imediata, nesse sentido, Roque Antônio Carazza (2011, p. 176). No entanto, para que sejam desde logo realizadas dependem das condições financeiras da municipalidade, que por seu turno, dependem das transferências exteriores. Nessa situação, 
o princípio da autonomia é atenuado, pois, ao depender de outro ente político, sofre também suas ingerências.

Além da autonomia 'vertical', que se revela entre os municípios e os outros entes federativos, existe também a autonomia 'horizontal' entre os municípios entre si, perante a Federação nenhum Município é mais importante do que o outro, ainda que aufira mais recursos econômicos.

O Município pode instituir e arrecadar seus tributos próprios, assim considerados os de sua competência, sem a interferência de qualquer outro ente, de forma que Roque Antônio Carazza (2011, p. 194) declara a inconstitucionalidade de algumas políticas como as chamadas 'listas de serviços' do ISS - imposto sobre serviço de qualquer natureza, que representam a ingerência de um membro federativo sobre o outro.

Enaltecendo a importância da autonomia financeira como primordial às demais, Antônio Roberto Sampaio Dória (1972, p. 11), preconiza que "o poder político, distribuído pelas camadas da Federação, encontra seu necessário embasamento na simultânea atribuição do poder financeiro, sem o qual de pouco vale: autonomia na percepção, gestão e dispêndio das rendas próprias." Em suma, requer-se que para cada atribuição partilhada o ente responsável também aufira a partilha de recursos necessários para executá-la.

Dessa forma, verifica-se que a autonomia está diretamente correlacionada à repartição de tributos, que deve ser condizente com as competências de cada membro federativo. Para tanto, Gilmar Ferreira Mendes e Paulo Gustavo Gonet Branco (2011, p. 1456) ilustram que existem duas formas de se assegurar a autonomia dos membros federativos, quais sejam, "partilhar competências tributárias e partilhar o produto da arrecadação."

As transferências têm finalidades precípuas da redução de desigualdades entre os entes com menor capacidade arrecadatória e a execução de projetos de interesse nacional. Tal repasse financeiro vem se tornando cada vez mais vital para a 'saúde econômica' dos Municípios, e sua finalidade tem se transmudado para 'socorro' ou auxílio político às bases eleitorais. Nessas condições não há que se falar em autonomia.

Ainda quanto às transferências, especula-se se a exigência de padrões mínimos de serviço para o repasse dos recursos voluntários transferidos com o objetivo da execução de alguma obra de caráter nacional representa atenuação do princípio da autonomia. 
Entende-se que tal política, assim como alguma vinculação da receita, desde que aconteça de forma a se considerar as peculiaridades de cada ente federal, se torna precípua para a devida aplicação dos recursos em áreas extremamente essenciais à população, pois, como representam interesses nacionais seria temerário relegar aos governantes de plantão ampla discricionariedade no tocante aos gastos com tais serviços.

Segundo Fernando Rezende e Fabrício Augusto de Oliveira (2003, p. 299), preconizam que o equilíbrio financeiro ideal se estabelece com a "combinação de autonomia orçamentária e vinculação de gasto." Pode-se acrescentar ainda que as transferências de finalidade equitativa são benéficas à Federação, na medida em que, visam tratar, materialmente, de forma igualitária os integrantes federativos.

A carência financeira dos Municípios, segundo Luís Roberto Barroso (2006, p. 145), não se deve apenas à repartição de rendas, mas também, à repartição de encargos. Aduz ainda, que no caso dos entes locais os impostos próprios lhes conferidos têm representatividade econômica apenas em municipalidades de indústria desenvolvida e localidades urbanas.

De acordo com uma análise sistemática do texto magno verifica-se que aos Municípios foram relegadas diversas competências, notadamente de caráter social, sem que, houvesse paralelamente, o aumento de sua capacidade tributária, desprestigiando a correspondência fiscal.

As distorções na repartição geram desequilíbrio político e fiscal à medida que tornam os entes menos favorecidos extremamente dependentes dos recursos externos para concretizar suas competências materiais e desenvolver-se garantindo ao menos, os serviços públicos básicos à sua população. Em busca de conseguir mais recursos para obter, consequentemente, maior capacidade de gasto, os Municípios buscam medidas que acabam por aumentar seu endividamento, onerando o contribuinte, bem como as outras entidades federativas, por meio da externalização de custos. Os principais instrumentos de obtenção de crédito são elencados pelo doutrinador supracitado como,

[...] financiamentos externos; disputa por recursos federais, sob a forma de créditos de órgãos e entidades oficiais, convênios, fundos, programas, repasses a fundo perdido ou gastos realizados diretamente nas unidades federadas; realização de gastos por empresas estatais, cuja natureza privada, além de outras particularidades, permitia acesso a fontes diversificadas de financiamento e a 
utilização dos bancos estaduais na alavancagem de recursos, [...] (BARROSO, 2006, p. 299).

Tais políticas desordenadas de obtenção de recursos têm sua gênese na ausência de recursos próprios suficientes. Além disso, o endividamento das municipalidades aprofundouse à medida que os créditos externos foram se tornando mais escassos e fiscalizados pela União e os gastos com servidores públicos (lato sensu) principalmente inativos aumentaram.

No que concerne aos Fundos de Participação dos Municípios, deve-se esclarecer que, a autonomia em sua utilização vêm sendo restringida através da vinculação, principalmente com a seguridade social. Corrobora com este entendimento João Francisco Neto (2009, p. 192), asseverando que "daí resulta que, enquanto crescia o volume de recursos transferidos e vinculados a gasto específicos, diminuía a importância das transferências de livre aplicação restringindo assim, a autonomia dos recursos que integram os orçamentos estaduais e municipais".

Registrando a negatividade da 'brecha vertical', Luís Roberto Barroso (2006, p. 149) se manifesta nos seguintes termos:

vive-se, portanto, um momento crítico na Federação brasileira e um gravíssimo problema de natureza fiscal, que tem comprometido o funcionamento adequado das instituições e serviços estaduais e municipais. O reconhecimento deste cenário é imperativo para qualquer atividade de interpretação e construção jurídicas acerca da matéria.

A autonomia financeira do Município contida no Art. 30, inc. III da Constituição Federação pode ser analisada sob diversos prismas, entretanto, o foco da pesquisa concentra-se no aspecto atinente à capacidade de obter por meio de receita própria renda suficiente para executar a despesa de sua titularidade.

\section{Considerações Finais}

Desde a primeira Constituição Republicana, promulgada em 1891, o Brasil elegeu constitucionalmente, a forma de Estado Federalista, inspirados os constituintes na experiência norte-americana. No entanto, não atentaram para as diferenças sociais, culturais e econômicas que distanciam as realidades de ambos os países, impossibilitando a adoção de formas de Estado idênticas. 
O impulso para a instauração do federalismo ocorreu de acordo com motivos diametralmente opostos no Brasil e nos Estados Unidos, fato que auxilia e explicar a concentração de competências da União brasileira e, diversamente, a maior autonomia dos estados-membros norte-americanos.

Com a promulgação da Constituição de 1946, passa a se iniciar uma evolução do pacto federativo brasileiro, visto que tal Carta Magna distancia-se do paradigma federalista adotado no princípio, à medida que o município ocupa maior relevância no pacto federativo tendo, constitucionalmente, sua autonomia reconhecida. Mas, somente com a Constituição Federal de 1988 é que teve o seu reconhecimento de status federativo (Art. 10 e Art. 18).

Tem se presente que os Municípios brasileiros percorreram longo caminho até o reconhecimento de seu status federativo, haja vista que no princípio da história federativa pátria eram considerados entes de terceiro grau, situando-se hierarquicamente abaixo de estados e União, ou ainda pior, meras unidades administrativas, onde o poder eleitoral dos demais entes era exercido.

Com a Constituição de 1946, as municipalidades, afinal, conseguiram, constitucionalmente sua autonomia. No entanto, com pesar, houveram por descobrir que a autonomia, preconizada na Carta Magna, consolidou-se apenas de modo formal, pois, embora os entes locais integrem o pacto federativo brasileiro e tenham competências legislativa, administrativa, organizacional e governamental, a autonomia financeira para custear todas as suas incumbências materiais não é alcançada, em virtude da disparidade entre suas receitas próprias e suas atividades públicas, notadamente, tendo em vista o fenômeno da descentralização de encargos para o Município.

Os estudos desta pesquisa levaram a concluir que o Brasil não vivencia as conquistas de uma federação de cooperação, uma vez que:

i) permanece a instalabilidade financeira em virtude da disparidade entre as receitas municipais próprias e suas atribuições, notadamente, tendo em vista o fenômeno da descentralização de encargos públicos para o Município e a centralização na distribuição das competências tributárias;

ii) os Municípios não têm representação legislativa no senado federal, assim, não participam de modo direto das decisões na formação da vontade nacional tal como ocorre com os estados-membros. Em razão dessa opção brasileira os municípios são atingidos por 
políticas econômicas e tributárias decididas no legislativo federal e que interferem em sua autonomia financeira, especialmente, na redução das transferências intergovernamentais.

iii) as transferências financeiras voluntárias não têm sido destinadas de acordo com um critério técnico, mas, por outro lado, vêm se constituindo em privilégios para a base governista.

A dependência econômica das municipalidades pode ser comprovada por meio de estudos ecônomico-financeiros das suas receitas. Essa situação não tem conotação apenas econômica, incidindo na atenuação da autonomia garantida constitucionalmente às Municipalidades.

Diante dessas circunstâncias, verifica-se que a federação brasileira ainda não está consolidada paritariamente entre todos os entes federativos, o Município se encontra dependente dos demais entes, em virtude de sua hipossuficiência econômica.

A hipossuficiência municipal se deve às escolhas do federalismo fiscal brasileiro, em parte, embasadas na forma centrífuga em que ocorreu a formação federativa brasileira, ou seja, primou-se pelo acúmulo de competências tributárias da União, que após auferir as rendas, deve repartir os resultados entre os demais integrantes da Federação, e como acima consignado, nessa operação deve se guiar por critérios técnicos que levem à equidade entre os entes de acordo com o federalismo cooperativo.

Para além das transferências intergovernamentais, uma opção viável aos Municípios para a consecução de suas competências materiais seriam os consórcios e os convênios, que, no entanto, não são incentivados pelo poder central.

Portanto, observa-se que, na ausência da autonomia financeira, as outras autonomias municipais ficam comprometidas, tornando-se apenas formalmente preconizadas.

\section{Referências}

ABRUCIO, Fernando Luiz; COSTA, Valeriano Mendes Ferreira. Reforma do Estado e o contexto Federativo Brasileiro. São Paulo: Konrad-Adenauer-Stiftung, 1998.

BARROSO, Luís Roberto. A derrota da federação: o colapso financeiro dos estados e municípios. In: BARROSO, Luís Roberto.Temas de Direito Constitucional. 2.ed. Rio de Janeiro: Renovar, 2006. 
CARRAZZA, Roque Antônio. Curso de Direito Constitucional Tributário. 27. ed. São Paulo: Malheiros, 2011.

DALLARI, Dalmo de Abreu. Elementos de teoria geral do Estado. 26.ed. São Paulo: Saraiva, 2007.

DIMOULIS, Dimitri (Coord.). Dicionário Brasileiro de Direito Constitucional. São Paulo: Saraiva, 2007.

FRANCISCO NETO, João. Responsabilidade Fiscal e Gasto Público no Contexto Federativo. 2009. 272 f. Tese (Doutorado em Direito Econômico e Financeiro) - Departamento de Direito Econômico, Financeiro e Tributário. Universidade de São Paulo. Faculdade de Direito. São Paulo, 2009,p. 51. Disponível em:

<http://www.teses.usp.br/index.php?option=com_jumi\&fileid=9\&Itemid=159\&lang=ptbr\&id=2133\&prog=2001\&exp=0>. Acesso em: 04 jan. 2012.

LIMA, Edilberto Carlos Pontes.Transferências orçamentárias da União para estados e municípios: determinantes e beneficiários. In: REZENDE, Fernando; OLIVEIRA, Fabrício Augusto de. (Org.). Descentralização e Federalismo Fiscal no Brasil: Desafios da Reforma Tributária. Rio de Janeiro: Konrad-Adenauer-Stiftung, 2003.

MENDES, Gilmar Ferreira; BRANCO, Paulo Gustavo Gonet. Curso de Direito Constitucional. 6. ed. São Paulo: Saraiva, 2011.

OLIVEIRA, Regis Fernandes de. Curso de Direito Financeiro. 2. ed. São Paulo: Revista dos Tribunais, 2008.

PRADO, Sérgio. Equalização e Federalismo Fiscal: uma análise comparada. Rio de Janeiro: Konrad-Adenauer-Stiftung, 2006.

Distribuição intergovernamental de recursos na Federação brasileira. In: REZENDE, Fernando; OLIVEIRA, Fabrício Augusto de. (Org.). Descentralização e Federalismo Fiscal no Brasil: Desafios da Reforma Tributária. Rio de Janeiro: Konrad-Adenauer-Stiftung, 2003.

Artigo recebido em 09/08/2012 e aprovado para publicação em 27/11/2012. 